\title{
Cancer Prevention Fellowship Program
}

National Cancer Institute

\section{Source}

National Cancer Institute. Cancer Prevention Fellowship Program. NCI Thesaurus. Code C18671.

The Cancer Prevention Fellowship Program provides for: Master of Public Health training, participation in the Cancer Prevention and Control Academic Course, mentored research, and brief field assignments in cancer prevention or cancer control programs at other institutions (from Cancer Prevention Fellowship Program/Description) 